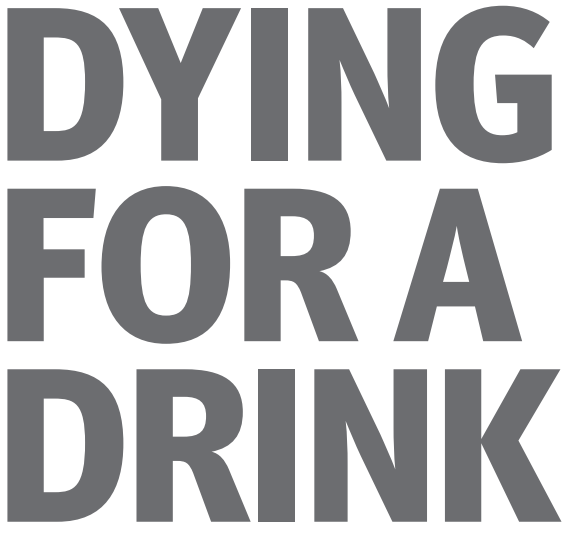

The water and sewerage systems built throughout Europe in the 19th century dramatically improved public health. But, as Kate Eshelby reports, the developing world is still waiting for the political will for a similar revolution

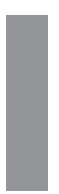

$\mathrm{n}$ the flat, arid plains surrounding the Nuba mountains, Sudan, a woman scoops drinking water from muddy puddles on the ground into a jerry can, loads the can onto a camel, and returns to her village. Scenes like this are repeated throughout sub-Saharan Africa and make it hard to understand why water and sanitation are not getting more global attention.

Diseases related to the lack of clean water are the second biggest killer of children under 5 years, two million dying every year from diarrhoea; 1.1 billion people do not have access to water and 2.6 billion are without sanitation. The United Nations' 2006 Human Development Report asserts that a global action plan under G8 leadership is desperately needed to resolve the growing crisis, but water and sanitation-which earlier this year topped a $B M J$ poll of the most important medical advances (BMJ 2007; 334:111)-remain absent from this year's G8 agenda. ${ }^{1}$ In an attempt to change this, the charity WaterAid is launching its End Water Poverty campaign on 26 March.

World governments committed to halving the proportion of people without safe drink-

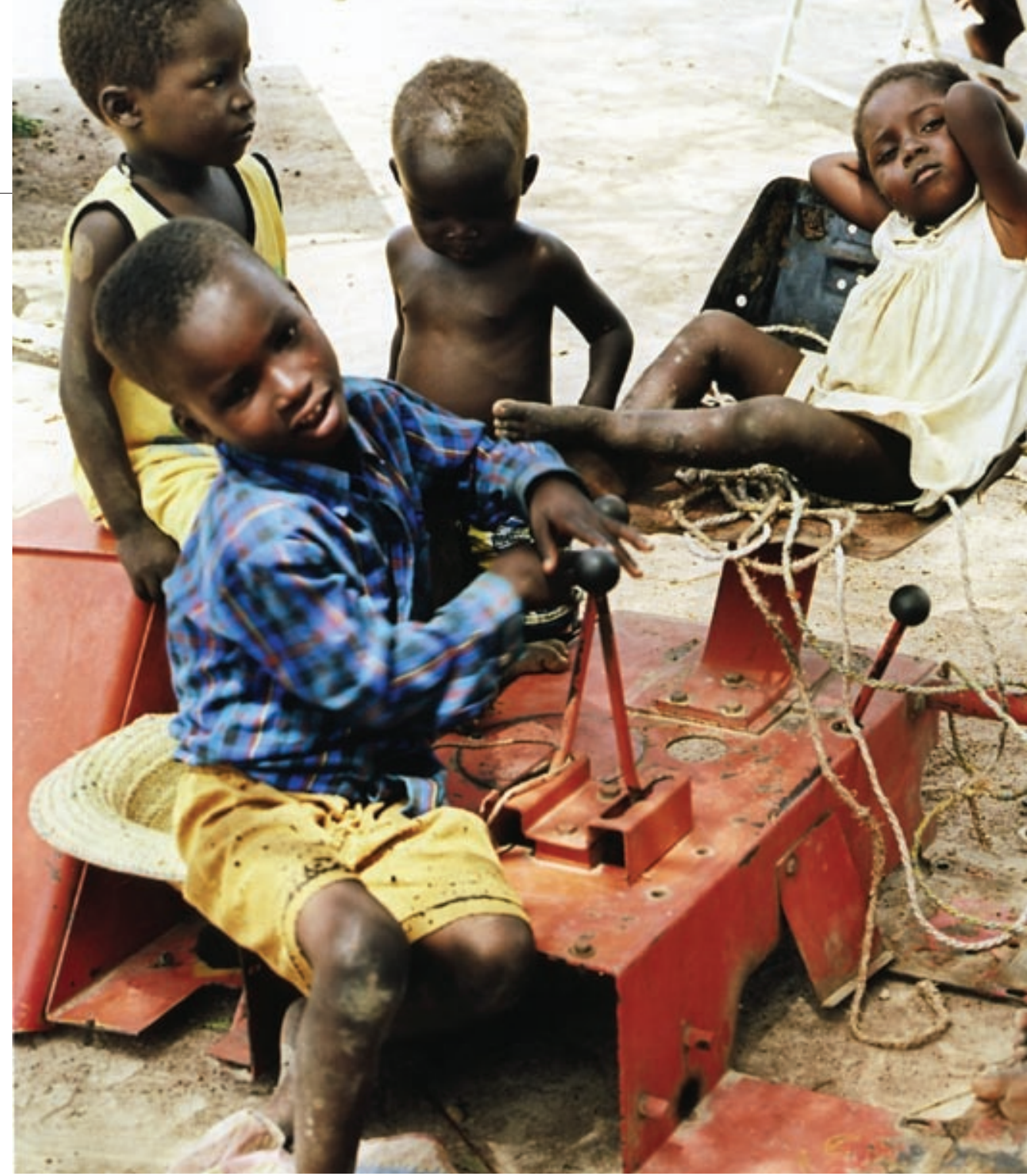

ing water and sanitation by 2015 as part of the millennium development goals, but progress has been slow. Sanitation is one of the worst performing goals, and although water supply has improved in many regions, there is still a long way to go in sub-Saharan Africa. The other goals-achieving universal primary education and reducing child and maternal mortality-are also unlikely to be reached because they are all closely linked with the basic needs of water and sanitation.

\section{Wider benefit}

Clean water and sanitation stop people dying, it is as simple as that. "They also reduce poverty; abating the number of sick days people spend unable to work or grow crops to feed their families, the amount of money they outlay on medicine, and the number of school days missed," explains Robert Guest, former Africa editor of the Economist. The Human Development Report estimates that the additional cost needed to achieve the millennium development goals on water and sanitation is $\$ 10 \mathrm{bn}(£ 5.2 \mathrm{bn}$; $€ 7.6 \mathrm{bn})$ a year-half what the developed world spends annually on mineral water. The
"People living without water and sanitation don't need 23 agencies to discuss a strategy - they need one international water monitoring body taking urgent action"

benefits far outweigh the costs; productivity losses linked to water and sanitation in sub-Saharan Africa amount to 5\% of gross domestic product annually - a lot more than it receives in aid.

There is little point in Gordon Brown investing $£ 15$ bn in education in developing countries if a third of children miss school because of diarrhoea. Girls are the worst off: additionally missing school to help their mothers fetch water or because a lack of water or latrines at most schools makes it hard for girls to attend, especially during menstruation.

In Britain sanitation came first and modern medical care followed, whereas in Africa the health sector has been prioritised. "Hospitals are of course vital but the basics, which prevent disease, need to come first. People in parts of Africa, especially in the ever- 


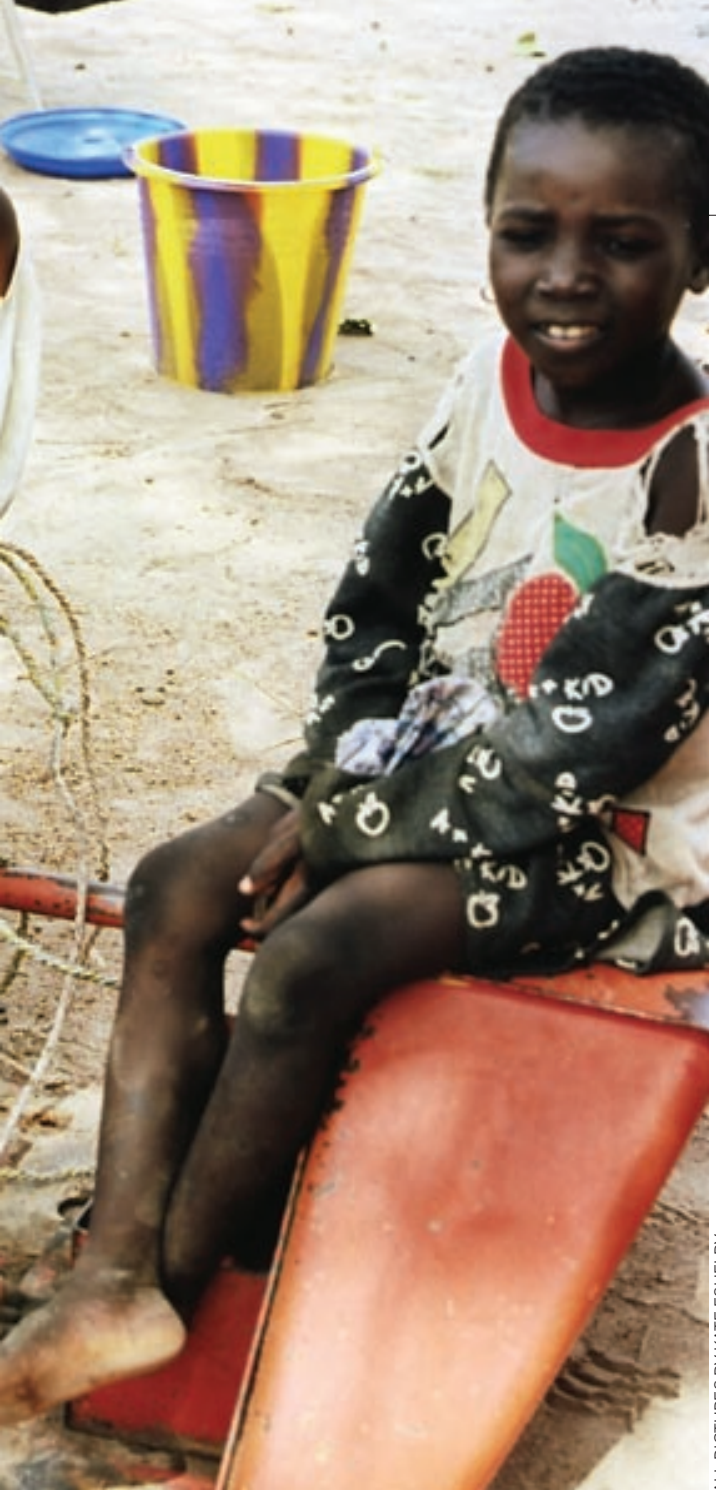

In drought hit areas (bottom, right), people are forced to collect dirty water (below, right). Lack of water for washing allows skin diseases to flourish (left)

Hilary Benn, the secretary of state for international development, announced the UK's recognition of the fundamental right to water. ${ }^{2}$ The department is doubling its funding for water and sanitation-in sub-Saharan Africa the amount will rise from $£ 47.5 \mathrm{~m}$ to $£ 95 \mathrm{~m}(€ 139 \mathrm{~m} ; \$ 183 \mathrm{~m})$ a year by 2008 . However, as aid has expanded in all sectors, others have got more in real terms. The increase will undoubtedly help, but priority needs to be given to water and sanitation before real improvements can be seen.

Some developing country governments have taken action themselves. "In Angola the government has increased the water supply coverage from $32 \%$ in 1990 to $50 \%$ in 2002, mainly in Luanda and other cities," Dauda Wurie, water and environmental sanitation project officer at Unicef, says. Another example is the Burkinabe government boosting Ouagadougou's water supply by building the Ziga dam, making it cheaper for people to connect to the national water and sewerage supply.

Governments have also made progress in changing hygiene behaviour by social marketing, stimulating community demand for sanitation. "In Ethiopia some people are afraid of latrines because of cultural beliefs so we do demonstrations, teaching them the connection between simple hygiene and preventing disease. They then want to build latrines," says Abdi Saliye, water and sanitation officer at International Committee for the Development of Peoples, a nongovernmental organisation based in Italy.

Non-governmental organisations have also helped. WaterAid is the UK's only major charity dedicated exclusively to providing safe water, sanitation, and hygiene education; it helps communities construct latrines, composting toilets (vital in countries with minimal networked sewerage), and clean water sources. Unicef supports water, sanitation, and hygiene education in schools and health services, as well as rural and low income communities. "We support national partners in ensuring that schools and health services promote growing slums, live in conditions where disease spreads like wildfire," Jonathan Kaplan, a war surgeon, says. Those with no latrines have to defecate in the open, polluting crops and water sources, and the waste disposal system is almost non-existent. Few people have the privilege of piped water, or clean water of any kind.

This environment leads to an inexhaustible list of diarrhoeal illnesses, deadly for young and malnourished people. Washing in and collecting water from contaminated sources cause millions of people to become infected with debilitating worms, like hookworms, schistosomes, and guinea worms. Guinea worms are found only in Africa, having been eliminated elsewhere by improving the water supply. Then there are diseases like scabies and trachoma, the leading cause of preventable blindness, that are provoked by people not being able to wash properly because of water scarcity.

\section{Government action}

The need for water and sanitation is undeniable, so what is being done to improve the situation? Last November
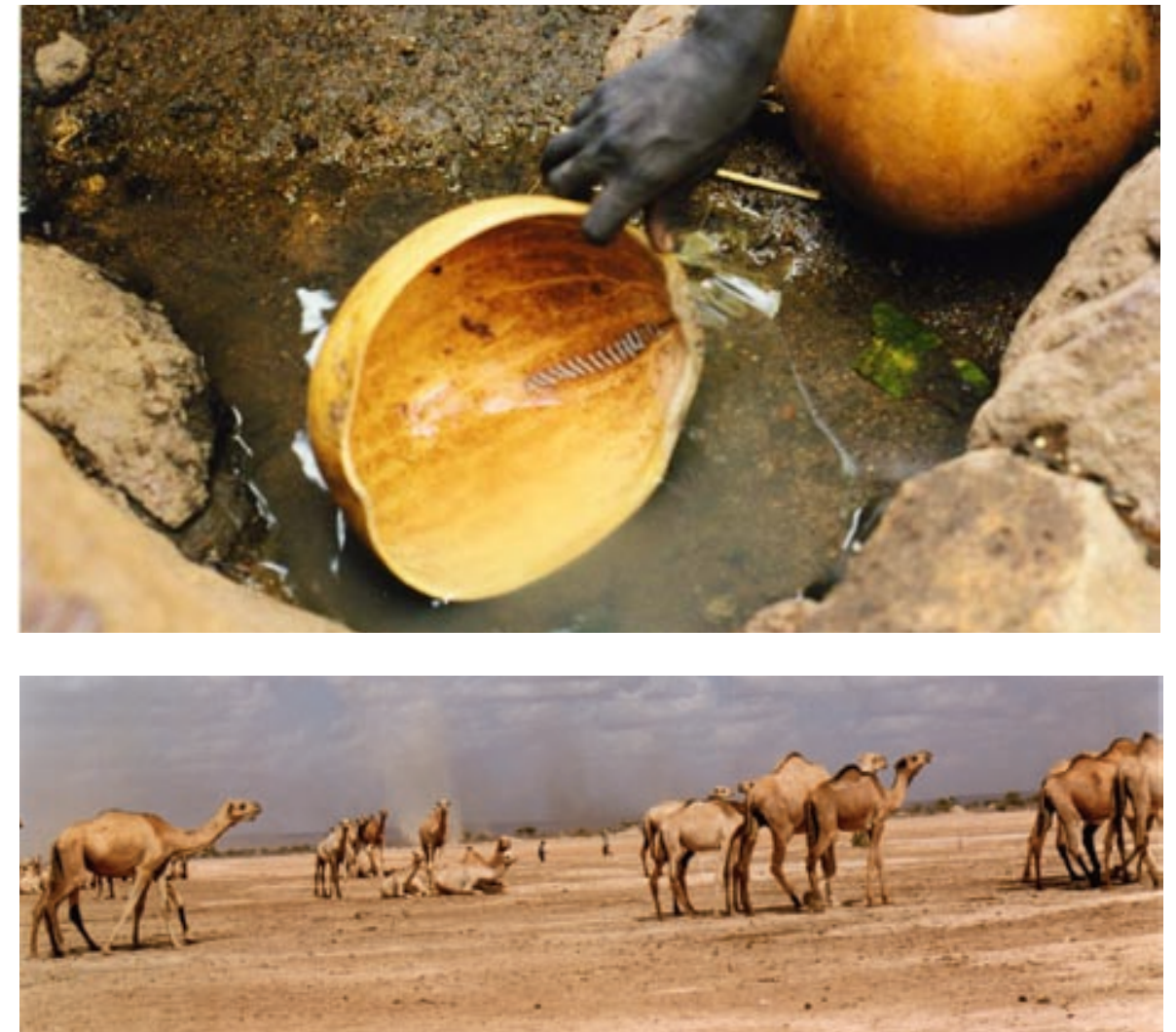

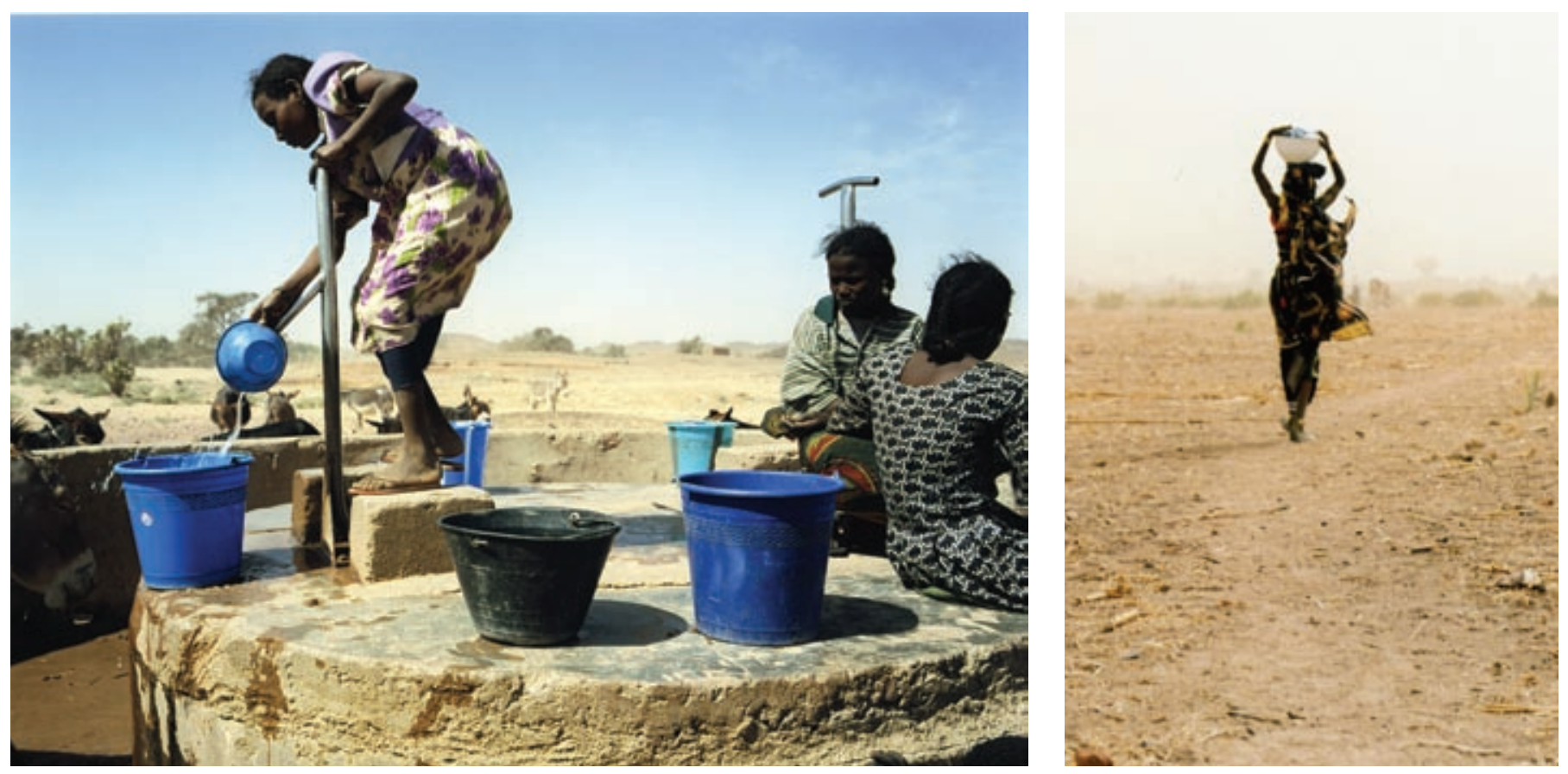

Residents of the oasis village of Timia in Niger now have a well built by the government, but in many parts of Africa people still have to walk miles to find water

improved hygiene practices and have access to improved basic sanitation; encouraging hand washing is pivotal to our work and promoting safe disposal of young children's excreta," Vanessa Tobin, deputy director at Unicef, explains.

\section{Barriers}

Work is therefore being done but no real headway is being made. The main reason for this is that sanitation and water have a low political status in developing countries. The services are provided by a diverse range of actors, with no single body taking full responsibility, resulting in inefficiency and weak national planning. Most governments spend little of their budget on these basic needs. Although sub-Saharan governments could alter their spending priorities, they still desperately need additional funds. But they are unable to get loans from international capital markets because of poor credit ratings, and water and sanitation are not seen as good long term investments. Many African countries need to create these services from nothing, after years of war have impeded development and destroyed the colonial water and sewerage systems.

Water and sanitation are not central on the development agenda either-they are usually prioritised only after emergencies, like a flood. "We cannot work on everything so we have to precedent other areas, like health and education," says John Magrath, a programme researcher at Oxfam. The bulk of available aid does not reach those who most need it anyway. Less than $40 \%$ of aid for water goes to countries where the majority of the population has no access to clean water. "Aid has strong political ties. The US gives aid to Iraq and Egypt, for example, or aid is linked to past colonial ties. The focus has not been on where the greatest need is," Stephen Turner, WaterAid's public policy and education director, says.

All the talk about water and sanitation often gets in the way of productive action. Countless international conferences are held to discuss the situation, and there are 23 different UN agencies dealing with water, but as Mr Benn says, "People living without water and sanitation don't need 23 agencies to discuss a strategy-they need one international water monitoring body taking urgent action." With climate change making water scarcity an increasingly global problem, the requirement for good water management has never been greater.

African governments usually have full control of public utilities, and allocation of resources to the politically powerful is rife. Thus rich city dwellers have safe water but those living in rural or poor urban areas do not. The poor, unable to afford connection to the national water supply, have to buy water from vendors or community fountains at inflated prices.

Water privatisation was encouraged by the World Bank and International Monetary Fund in the 1990s, debt cancellations some- times relying on it. Although some countries do have successful private involvement with public companies, it is important that individual countries choose their own policies. Roger Bate, resident fellow at the American Enterprise Institute for Public Policy Research, a US based think tank, is in favour of privatisation, explaining, "Governments favour politically powerful groups, such as farmers. But with no private ownership of water, farmers grossly over use it, resulting in shortages for others-a big problem because agriculture uses $70 \%$ of the world's fresh water. When farmers, however, can trade part of their water quota they have an incentive to conserve it. This has proved successful in South Africa.”

Water and sanitation are fortunately starting to receive attention, with 2008 earmarked the international year of sanitation. Millions of children dying because they have no water and sanitation needs to be treated with the same urgency as a national emergency. Let's hope all the talking and earmarking leads to some results for those who really need it.

Kate Eshelby is a journalist. kate@kateeshelby.com Competing interests: None declared.

1 United Nations. Human development report 2006. Beyond scarcity: power, poverty, and the global water crisis. http://hdr.undp.org/hdr2006/.

2 Department for International Development. UK recognises the right to water as Hilary Benn launches call for Global Action Plan to solve water crisis. Press release 9 Nov 2006. Www.dfid.gov.uk/news/files/ pressreleases/human-dev-report06.asp. 